\title{
Myelin Gene Expression after Experimental Contusive Spinal Cord Injury
}

\author{
Jean R. Wrathall, ${ }^{1}$ Wen $\mathrm{Li}^{2}{ }^{2}$ and Lynn D. Hudson ${ }^{2}$ \\ ${ }^{1}$ Neurobiology Division, Department of Cell Biology, Georgetown University, Washington, DC 20007, and 2Laboratory of \\ Developmental Neurogenetics, National Institute for Neurological Disorders and Stroke, Bethesda, Maryland 20892
}

\begin{abstract}
After incomplete traumatic spinal cord injury (SCI), the spared tissue exhibits abnormal myelination that is associated with reduced or blocked axonal conductance. To examine the molecular basis of the abnormal myelination, we used a standardized rat model of incomplete $\mathrm{SCl}$ and compared normal uninjured tissue with that after contusion injury. We evaluated expression of mRNA for myelin proteins using in situ hybridization with oligonucleotide probes to proteolipid protein (PLP), the major protein in central myelin; myelin basic protein (MBP), a major component of central myelin and a minor component of peripheral myelin; and protein zero (P0), the major structural protein of peripheral myelin, as well as myelin transcription factor 1 (MYT1). We found reduced expression of PLP and MBP chronically after $\mathrm{SCl}$ in the dorsal, lateral, and ventral white matter both rostral and caudal to the injury epicenter. Detailed
\end{abstract}

studies of PLP at 2 months after injury indicated that the density of expressing cells was normal but mRNA per cell was reduced. In addition, P0, normally restricted to the peripheral nervous system, was expressed both at the epicenter and in lesioned areas at least $4 \mathrm{~mm}$ rostral and caudal to it. Thus, after $\mathrm{SCl}$, abnormal myelination of residual axons may be caused, at least in part, by changes in the transcriptional regulation of genes for myelin proteins and by altered distribution of myelin-producing cells. In addition, the expression of MYT1 mRNA and protein seemed to be upregulated after $\mathrm{SCl}$ in a pattern suggesting the presence of undifferentiated progenitor cells in the chronically injured cord.

Key words: myelin; spinal cord injury; mRNA; proteolipid protein; myelin basic protein; protein zero; myelin transcription factor 1; in situ hybridization; Western analysis; immunocytochemistry
Traumatic spinal cord injury (SCI) results in loss of tissue including important myelinated fiber tracts carrying descending motor and ascending sensory information. However, in $\sim 50 \%$ of patients, the injury is incomplete because some residual function remains (Bracken et al., 1990). In animal models of incomplete SCI, the residual white matter in the chronic injury site has been found to be hypomyelinated, and this has been associated with abnormal impulse conduction properties of surviving axons (Blight, 1983a,b). There is also evidence of abnormal myelination after human SCI (Bunge et al., 1993). That such abnormalities contribute to functional impairment in human SCI is indicated by the beneficial effect of treatment with 4-aminopyridine (Hansebout et al., 1993; Hayes et al., 1994), a potassium channel blocker that restores conduction in deymyelinated internodes.

A demyelination-remyelination sequence of events has been postulated to account for chronic hypomyelination after SCI (for review, see Blight, 1993). Demyelinated axons have been observed in the cord after experimental SCI (Gledhill et al., 1973;

Received April 27, 1998; revised July 20, 1998; accepted Aug. 14, 1998.

This work was supported by National Institutes of Health Grants NS28130 and NS35647 to J.W. and by intramural National Institute for Neurological Disorders and Stroke funds. We thank Dr. Arnulf Koeppen (VA Medical Center, Albany, NY) for the MBP antibody used in, and Dr. Richard Quarles for teaching us his protocol for, Western blot analysis of MBP. The densitometric analysis was performed in the Lombardi Cancer Center's Macromolecular Synthesis and Sequencing Shared Resource, supported in part by United States Public Health Service Grant P30-CA51008. Excellent technical assistance during the course of these studies was provided by Lily Verma, David Choiniere, and Robert Marriott. We also thank Carolyn Feltes for the MBP immunocytochemistry that she performed during a research rotation in the laboratory.

Correspondence should be addressed to Dr. Jean Wrathall, Department of Cell Biology, Georgetown University, 3900 Reservoir Road, Northwest, Washington, DC 20007.

Copyright (C) 1998 Society for Neuroscience $\quad 0270-6474 / 98 / 188780-14 \$ 05.00 / 0$
Griffiths and McCulloch, 1983; Bunge et al., 1994). Loss of oligodendrocytes by apoptotic mechanisms has recently been demonstrated (Li et al., 1996; Crowe et al., 1997; Liu et al., 1997; Shuman et al., 1997), which could contribute to aberrant remyelination of residual axons. However, the regulation of genes for myelin proteins in surviving oligodendrocytes may also be affected by SCI. To explore this hypothesis, we used in situ hybridization to examine the expression of genes involved in myelination after a standardized incomplete experimental spinal contusion injury.

Myelin in the CNS is characterized by two major structural proteins (for review, see Hudson, 1990). Proteolipid protein (PLP) accounts for $\sim 50 \%$ of CNS myelin protein. Myelin basic protein (MBP) constitutes $30 \%$ of CNS myelin protein and is also a minor component (5-15\%) of peripheral nervous system (PNS) myelin. The major protein of PNS myelin, protein zero (P0), is not normally detected in the spinal cord. However, P0 might be expected in pathological situations such as SCI characterized by Schwann cell invasion of the CNS (Griffiths and McCulloch, 1983). In recent years transcription factors that seem to be involved in the coordinate regulation of expression of the program of genes for myelin synthesis have been identified. The first of these, myelin transcription factor 1 (MYT1), is a zinc finger protein (Kim and Hudson, 1992) that has been shown to be expressed not only in developing oligodendrocytes (Armstrong et al., 1995) but also in many glial tumors and in areas of the CNS where progenitor cells are found (Armstrong et al., 1997). To the extent that remyelination after SCI may involve the differentiation of progenitor cells into new oligodendrocytes to replace those lost by injury, we might expect increased expression of MYT1. We therefore used oligonucleotide probes to PLP, MBP, 


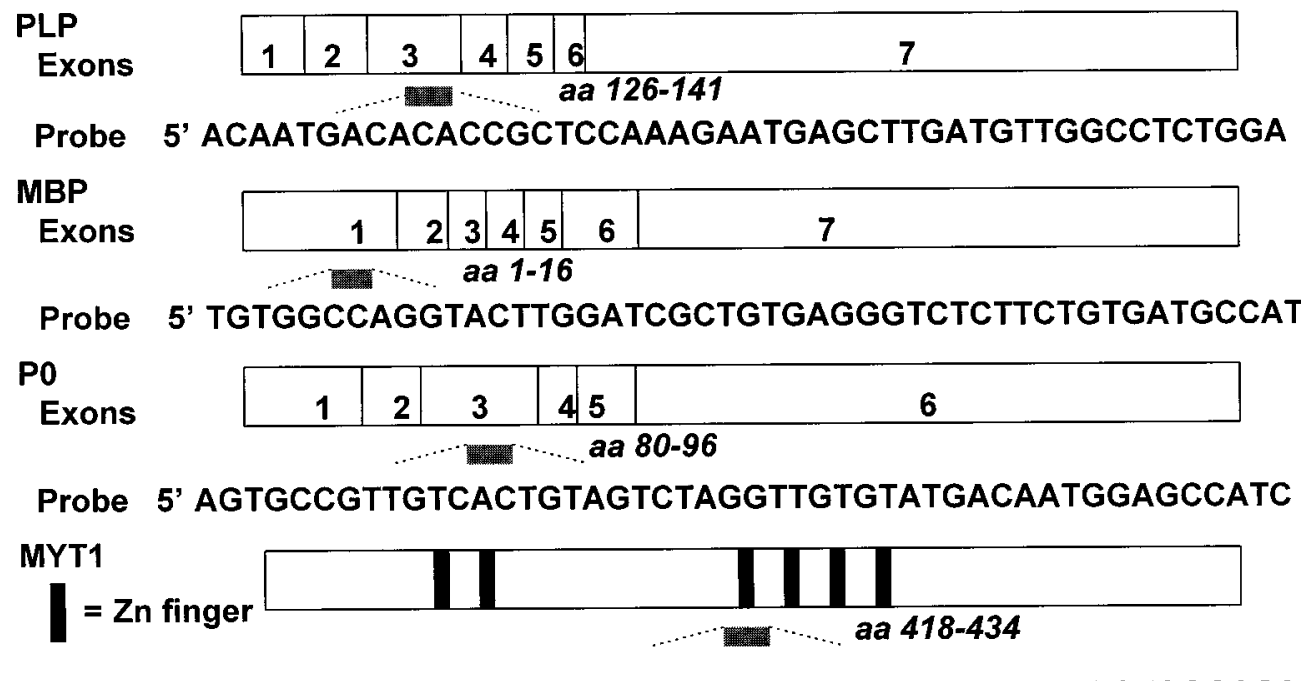

Probe 5' GTAGTTCCCGgTGATGTGGCCGCTGCCGTCACAGCCAGGGTGGGACA
Figure 1. Oligonucleotide probe sequences used and the location of these sequences in their respective genes.
P0, and MYT1 to examine expression of these myelin-related genes after a standardized incomplete spinal cord contusion injury in the rat.

\section{MATERIALS AND METHODS}

Spinal cord injury. A standardized contusive experimental SCI was produced in adult Sprague Dawley rats as described previously (Wrathall et al., 1985). Briefly, a $10 \mathrm{gm}$ weight was allowed to drop $2.5 \mathrm{~cm}$ onto a impounder (2.4-mm-diameter tip) resting on exposed dura at the T8 vertebral level to produce a contusion injury. This results in an incomplete chronic lesion characterized at the epicenter by a central cavity devoid of normal CNS tissue and a peripheral rim of residual white matter (Noble and Wrathall, 1985, 1989).

Our previous studies with this model have shown hindlimb paralysis and areflexia at $1 \mathrm{~d}$ followed by partial recovery of function that stabilizes to reveal the chronic functional deficits by 3 weeks after injury (Gale et al., 1985; Wrathall et al., 1985). Functional deficits correlate with loss of spinal cord tissue at the epicenter, the region of maximal damage at the injury site (Noble and Wrathall, 1985, 1989). By 2 months after injury, a typical lesion extends from the epicenter longitudinally for 10-12 mm, with the lesion area tapering rostrocaudally to a small region in the dorsal white matter.

Electron microscopy. To characterize chronic histopathology further, three rats at 2 months after SCI and four normal controls were anesthetized and perfused with saline followed by fixative solution $(2 \%$ glutaraldehyde, $2 \%$ paraformaldehyde, and $2 \mathrm{mM} \mathrm{CaCl}_{2}$ in $0.1 \mathrm{M}$ cacodylate buffer, $\mathrm{pH} 7.3$ ). A tissue chopper was used to prepare $200 \mu \mathrm{m}$ crosssections that were post-fixed (1\% osmium and $1.5 \%$ potassium ferricyanide in cacodylate buffer for $2 \mathrm{hr}$ ), stained en bloc with uranyl acetate, dehydrated, and flat embedded in Araldite resin (Ted Pella, Redding, CA). One micrometer sections through the lesion epicenter were cut with glass knives on an ultramicrotome, stained with toluidine blue, and examined by light microscopy. Smaller blocks were prepared that represented specified regions of the epicenter, and 50-70 $\mathrm{nm}$ thin sections were cut with a diamond knife and mounted on copper grids. After they were stained with lead citrate, the sections were viewed in a JOEL (Tokyo, Japan) 1200 EX electron microscope.

For quantitative analyses of myelinated axons, electron micrographs of ventromedial white matter were prepared at an original magnification of $2000 \times$ and printed all with the same enlargement. For each rat, micrographs representing different grid squares of a single section were randomly selected for quantitative analysis. Each myelinated axon whose cross-section could be seen in its entirety was measured in terms of the diameter of the axoplasm (A) and the diameter of the axon plus myelin (AM). Myelin index (MI) was calculated as MI $=\mathrm{A} / \mathrm{AM}$.

In situ hybridization. At 1 week, 2 months, and 6 months after SCI, rats were killed by decapitation, and spinal cords from injured rats $(n=3$ at each time point) and normal controls were rapidly removed. The tissue was frozen in blocks that contained both one uninjured control and one or more injured spinal cords (e.g., cords at different times after injury). Serial $12 \mu \mathrm{m}$ cross-sections were prepared on a cryostat, thaw mounted on slides coated with 3-aminopropyltriethoxysilane (Sigma, St. Louis, MO), and stored frozen until they were used for in situ hybridization. Slides representing each millimeter length of cord were stained with luxol blue and counterstained with hematoxylin and eosin and used to reconstruct the injury site, as described previously (Noble and Wrathall, 1989; Teng and Wrathall, 1997). Based on this, a series of slides representing the lesion epicenter and specified distances rostral and caudal to it was selected for hybridization with the various probes.

Oligonucleotide antisense sequences with a length of 48 bases were used as probes for the following genes associated with myelination (Hudson, 1990): P0, the major structural protein of PNS myelin (50\%); PLP, a major protein of CNS myelin (50\%); and MBP, a major component of CNS (30\%) and a minor component of PNS (5-15\%) myelin. In addition we probed for myelin transcription factor 1 (MYT1) that is expressed in developing oligodendrocytes and seems to be involved in the coordinate expression of genes for myelin proteins (Hudson et al., 1997). Figure 1 shows the probe sequences and the location of these sequences in their respective genes. The oligonucleotides were labeled with $\mathrm{S}^{35}$-dATP homopolymer tails using terminal deoxynucleotidyl transferase (Stratagene, La Jolla, CA). For in situ hybridizations, slides were post-fixed with $4 \%$ formaldehyde in PBS, pH 7.4, for $10 \mathrm{~min}$, acetylated $(0.25 \%$ acetic anhydride in $0.1 \mathrm{M}$ triethanolamine $\mathrm{HCl}, \mathrm{pH} 8$, for $10 \mathrm{~min}$ ), and dehydrated with graded alcohols and chloroform. They were then incubated overnight at $37^{\circ} \mathrm{C}$ with hybridization buffer $(50 \%$ formamide, $600 \mathrm{~mm} \mathrm{NaCl}, 80 \mathrm{~mm}$ Tris- $\mathrm{HCl}$, pH 7.5, 4 mu EDTA, 0.1\% sodium pyrophosphate, $0.2 \%$ SDS, $0.2 \%$ sodium heparin, $10 \%$ dextran sulfate, and $100 \mathrm{~mm}$ dithiothreitol) containing $0.5-1 \times 10^{5} \mathrm{cpm}$ per $\mu \mathrm{l}$ of $\mathrm{S}^{35}$-labeled probe. The next day the slides were washed sequentially with $1 \times \operatorname{SSC}(0.15 \mathrm{M} \mathrm{NaCl}$, and $15 \mathrm{~mm}$ sodium citrate, $\mathrm{pH} 7.0), 2 \times \mathrm{SSC}$ with $50 \%$ formamide (four times for $15 \mathrm{~min}$ each at $\left.40^{\circ} \mathrm{C}\right)$, and $1 \times \mathrm{SCC}(60$ min ambient) and then dehydrated and allowed to air dry. The slides were dipped in Kodak (Rochester, NY) NTB2 liquid photographic emulsion, exposed in the dark at $4^{\circ} \mathrm{C}$ for $6-14 \mathrm{~d}$, and then developed and counterstained lightly with hematoxylin or hematoxylin and eosin.

Quantification was performed with slides exposed for a short period (e.g., $6 \mathrm{~d}$ ) to limit the number of grains and thus errors of coincidence. Grains were counted with the aid of a Zeiss IBAS image analysis system, in which control and injured tissue sections were compared on the same slide and background counts from slide areas devoid of tissue were subtracted. For area counts, a rectangular template encompassing 7912 $\mu \mathrm{m}^{2}$ was placed at specified positions in the ventral, lateral, or dorsal funicular white matter on both left and right sides of the tissue section, and counts were taken from the template areas in at least three section 

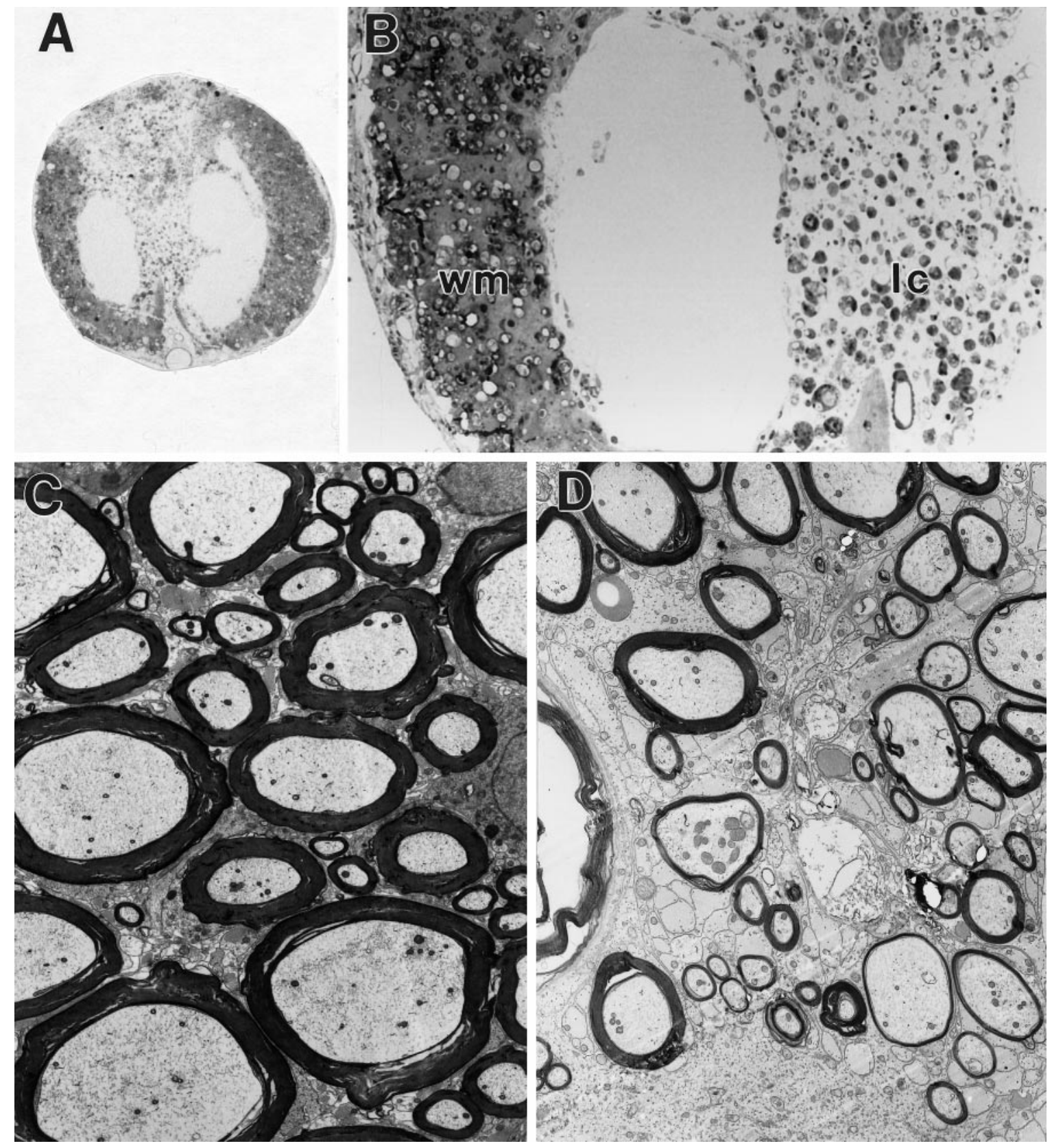

Figure 2. The injury epicenter at 2 months after incomplete contusive SCI. $A$, One micrometer plastic section showing the partial peripheral rim of residual white matter surrounding a central lesion cavity containing a loose accumulation of cells. $22 \times$. $B$, Higher magnification showing residual white matter $(\mathrm{wm})$, central cavity, and cells in the lesioned area $(l c) .80 \times . C, D$, Electron micrographs of ventral white matter from a normal uninjured spinal cord $(C)$ and a lesion epicenter $(D)$. 5000×. Compared with normal, the residual white matter of the chronic epicenter demonstrates reduced axon density interspersed with hypertrophic astrocytic processes resulting in a pale interaxonal matrix. Large axons are conspicuously absent, and the myelination of the remaining axons is frequently thinner than normal.

pairs per slide. For evaluating PLP grains per cell, a circular template delimiting an area of $227 \mu \mathrm{m}^{2}$ was centered on each sequential hematoxylin-stained nucleus in the specified white matter areas, and counts were recorded from these as well as nearby background areas devoid of tissue. All cell areas with counts less than the average background were considered unlabeled cells. Counts of net grains and the number of labeled or unlabeled cells were compared for the sampled areas $(n=6-8)$ of injured and control tissue sections on the slide by the use of Student's $t$ test $(p<0.05)$.

Western analysis. Protein levels for MBP in spinal cord tissue at 2 months after SCI were compared with those in laminectomy controls. For Western analysis, rats ( $n=5$ per group) were decapitated, and $2 \mathrm{~cm}$ lengths of spinal cord centered on $\mathrm{T} 8$ (the injury site) were rapidly removed, weighed, and frozen at $-70^{\circ} \mathrm{C}$ until used. Tissue homogenates were prepared in $0.32 \mathrm{M}$ sucrose using a Kontes Dounce homogenizer (Fisher Scientific, Houston, TX), a myelin fraction was prepared by sucrose density centrifugation (Norton and Poduslo, 1973), and protein concentrations were determined (Lowry et al., 1951). Myelin fraction samples (4.5 $\mu \mathrm{g}$ of total protein per well) and MBP (M 1891; Sigma) standards were subjected to SDS-acrylamide electrophoresis (Laemmli and Favre, 1973) and transferred onto nitrocellulose filters. MBP was detected with a polyclonal rabbit anti-bovine MBP (1:1000) generously provided by Dr. John Whittaker (Birmingham, AL), using a peroxidaseconjugated goat anti-rabbit IgG (Amersham, Arlington Heights, IL) as the secondary antibody. LumaGLO (Kierkegaard \& Perry, Gaithersburg, MD) chemiluminescent substrate was used, and the reaction was 


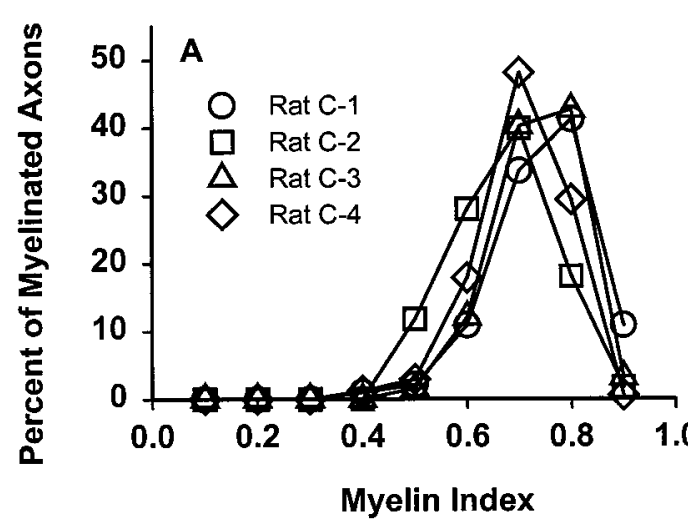

detected with Hyperfilm-MP autoradiography film (Amersham) and quantified by densitometry using PDI Discovery System (PDI, Huntington Station, NY) scanner and software, based on curves calculated from the MBP standards run with each gel. Values for injured and control samples ( $n=5$ each group) were compared by the use of Student's $t$ test. A $p$ value of $<0.05$ was considered significant.

Immunocytochemistry. For MBP immunocytochemistry, rats at 2 months after injury $(n=4)$ and uninjured controls $(n=2)$ were anesthetized and perfused intracardially with saline followed by $4 \%$ phosphate-buffered paraformaldehyde, $\mathrm{pH}$ 7.4. After fixation for an additional hour, $1.5 \mathrm{~cm}$ lengths of spinal cord tissue centered at T8 (the injury site) were cryoprotected by transfer through 10-30\% sucrose solutions and frozen in blocks that contained both normal and injured tissue; serial cross-sections $(20 \mu \mathrm{m})$ were prepared and stored frozen until used. The lesion was reconstructed by staining slides representing each millimeter of tissue with luxol blue, hematoxylin, and eosin; additional slides representing the epicenter and levels 2 and $4 \mathrm{~mm}$ rostral and caudal to it were used for MBP immunocytochemistry. These slides were air dried and then fixed for $10 \mathrm{~min}$ with $10 \%$ buffered formalin. After washes with PBS containing 1\% Triton X-100 (TPBS), they were dehydrated through graded alcohols and xylene, washed with TPBS, and air dried. After being blocked with hydrogen peroxide and normal goat serum, they were incubated overnight at $4^{\circ} \mathrm{C}$ with rabbit anti-MBP (catalog \# 08-0038; Zymed, San Francisco, CA), and the antigenantibody complex was detected using the Zymed Histostain-SP kit.

Immunohistochemistry was also performed on normal tissue and tissue at 6 weeks after SCI $(n=3)$ using $\alpha$ MYT1-his polyclonal rabbit antibody (Armstrong et al., 1995) and $\alpha$ MYT1L rabbit polyclonal antibody (Kim et al., 1997) essentially according to the avidin-biotin peroxidase complex (ABC) method described by Hsu et al. (1981). To block endogenous peroxidase activity and nonspecific immunostaining, we immersed sections in Tris-buffered saline (TBS) containing 3\% hydrogen peroxide before treating them with $10 \%$ normal goat serum containing $1 \%$ bovine serum albumin and $0.1 \%$ sodium azide for $40 \mathrm{~min}$ at room temperature. Sections were incubated with primary antibody (1:50 dilution for MYT1; 1:400 dilution for MYT1L) overnight at $4^{\circ} \mathrm{C}$. After incubation with biotinylated goat anti-rabbit IgG (Vector Laboratories, Burlingame, CA) for $40 \mathrm{~min}$ at room temperature, the avidinbiotin peroxidase complex reagent in a Vectastain Elite kit (Vector Laboratories) was applied according to the manufacturer's instructions, using a freshly prepared $0.05 \%$ diaminobenzidine solution containing $0.01 \% \mathrm{H}_{2} \mathrm{O}_{2}$. All TBS buffers contained $0.1 \%$ Triton X-100. Double immunostaining for the glial markers GFAP (astrocytes), CC1 [oligodendrocytes (Bhat et al., 1996; Shuman et al., 1997)], or OX42 (microglia) and MYT1 was also performed with enzymatic methods. The monoclonal anti-GFAP (1:50 dilution; Boehringer Mannheim, Indianapolis, IN), anti-CC1 (1:1000 dilution; APC-7; Oncogene Research Products, Cambridge, MA), or OX42 (Serotec, Harlan, Westbury, NY: 1:1000 dilution) antibodies were detected by alkaline phosphatase anti-mouse IgG (Promega, Madison, WI), and polyclonal MYT1 was detected by the horseradish peroxidase system (Vector Laboratories).

\section{RESULTS}

\section{Hypomyelination in the chronic injury site at 2 months} after SCI

The injury epicenter (Fig. $2 A$ ) typically contained a central cavity devoid of normal spinal tissue but containing variable numbers of
Figure 3. The myelin index (ratio of axon diameter to the diameter of the axon plus its myelin sheath) of axons in normal and chronic SCI ventromedial white matter. $A$, The index showed an approximately normal distribution with a peak at 0.7 or 0.8 for axons in the ventromedial white matter of four normal rats $(n=92-124$ axons per rat $)$. $B$, The distribution curves appeared wider and peaked at a higher ratio (thinner myelin), ranging from 0.8 to 0.9 , in the preserved ventromedial white matter in three rats at 2 months after SCI $(n=$ $100-167$ axons per rat). non-neuronal cells (Fig. 2B). These included large numbers of debris-laden macrophages as well as vascular elements and glia (see also Fig. 10). The central lesion was surrounded by a peripheral rim of residual white matter. By electron microscopy, the residual white matter appeared abnormal (Fig. 2D). Hypertrophied astrocytic processes produced a pale matrix of interaxonal material. Compared with uninjured controls (Fig. $2 C$ ), there was an obviously reduced number of axons, especially large axons. Although the residual axons were myelinated by oligodendrocytes, as expected, many axons appeared to be hypomyelinated (Fig. 2D); occasionally, some also seemed to have myelin sheaths that were thicker than normal (data not shown).

The myelin index (ratio of axon diameter to axon diameter plus its myelin sheath) showed an approximately normal distribution with a peak at 0.7 or 0.8 for axons in the ventromedial white matter of four normal rats (Fig. 3A). The distribution curves appeared wider and peaked at a higher ratio (thinner myelin) ranging from 0.8 to 0.9 in the preserved ventromedial white matter of three rats at 2 months after SCI (Fig. $3 B$ ). The average myelin index was not significantly different with the sample size studied. However, the proportion of axons with very thin myelin sheaths (myelin index $\geq 0.9$ ) was significantly greater (Student's $t$ test, $p=0.026)$ in the injured group $(31.9 \pm 10.4 \%)$ than in uninjured controls $(3.7 \pm 2.1 \%)$.

\section{PLP and MBP gene expression after SCl}

In normal adult rat spinal cord, there was a stereotypic pattern of myelin gene expression, as shown in Figure 4. PLP mRNA was heavily expressed as clumps of grains in the white matter and to a lesser extent in the gray matter but was not detected in peripheral nerve roots. MBP mRNA was strongly expressed as evenly distributed grains in the white matter. Its expression in the spinal cord showed a regional distribution that was similar to PLP with reduced expression in the gray matter. It was also expressed in peripheral nerve roots. P0 mRNA was seen only in peripheral nerve roots in which a clumped distribution was the characteristic pattern.

All tissue examined after SCI at $7 \mathrm{~d}, 2$ months, or 6 months after injury showed reduced PLP and MBP expression compared with that in uninjured control tissue on the same slide (Fig. 5). The reduced expression was seen in sections representing the injury epicenter (see Fig. 10B) and up to $6 \mathrm{~mm}$ rostral and caudal to the epicenter, the farthest distance at which tissue was examined. Quantification of the effect of SCI on PLP and MBP expression is shown in Figure 6 for a representative pair of normal and injured spinal cords with tissue sections at $\pm 4 \mathrm{~mm}$ from the lesion epicenter at 2 months after SCI. White matter in the dorsal, lateral, and ventral funiculi both rostral (Fig. 6A,B) 


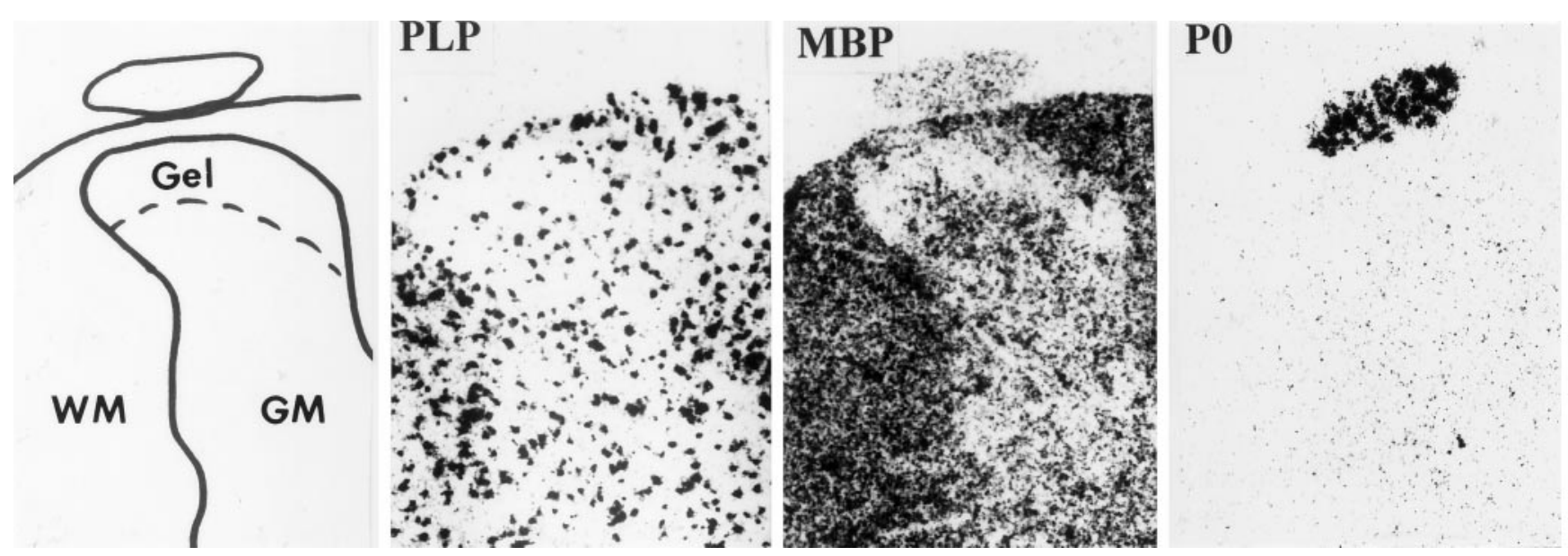

Figure 4. Pattern of myelin gene expression in normal adult rat spinal cord. Diagram of the dorsal horn region of a spinal cord cross-section indicates the location of gray matter $(G M)$ of the dorsal horn with the superficial substantia gelatinosa $(\mathrm{Gel})$ that is devoid of myelin, lateral-myelinated white matter $(W M)$, and, external to the cord, a portion of a peripheral dorsal nerve root. Sequential serial sections hybridized with probes for myelin structural protein genes show PLP expression absent in the nerve root and substantia gelatinosa but heavily expressed in the white matter with a clumped pattern. MBP expression has a similar distribution in the spinal cord, but grains are more dispersed; MBP also shows some expression in the dorsal root. P0 is not seen in the spinal cord but is heavily expressed in a clumped pattern in the dorsal root. $44 \times$.
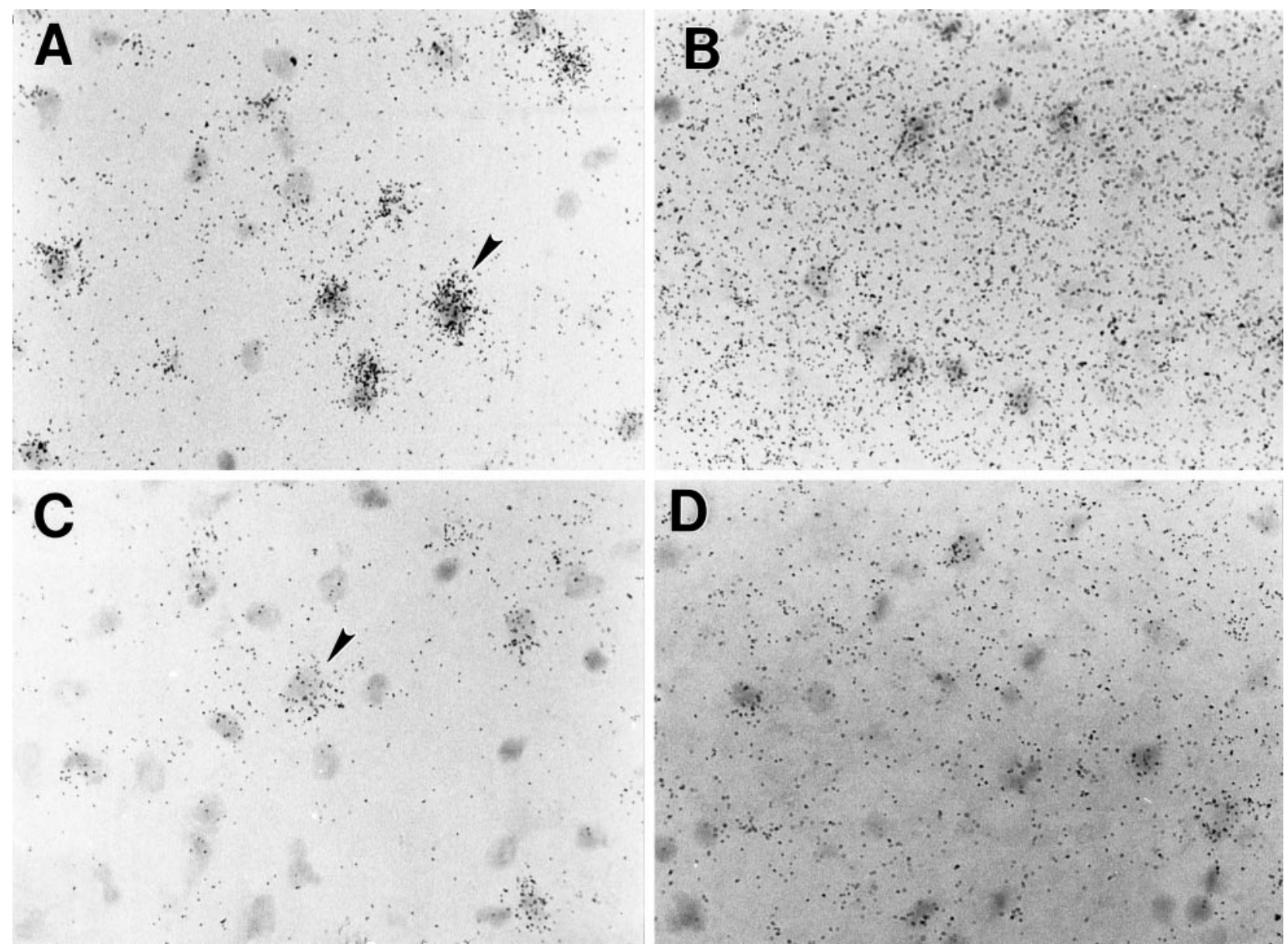

Figure 5. Reduced expression of PLP and MBP mRNA chronically after SCI. A, PLP expression in normal uninjured ventromedial white matter is primarily seen as grains associated with a subset of nuclei in the white matter. $B$, MBP expression is more evenly distributed over nuclei and cell processes. $C$, PLP expression shows the same distribution but appears reduced in amount in a section that is $4 \mathrm{~mm}$ caudal to the epicenter from a cord at 2 months after SCI and that was mounted on the same slide shown in $A$. D, MBP expression that is 4 mm caudal to the epicenter is also reduced as seen in this section of injured tissue from the same slide shown in B. A-D, 158×. Arrowheads, PLP-positive cells. 

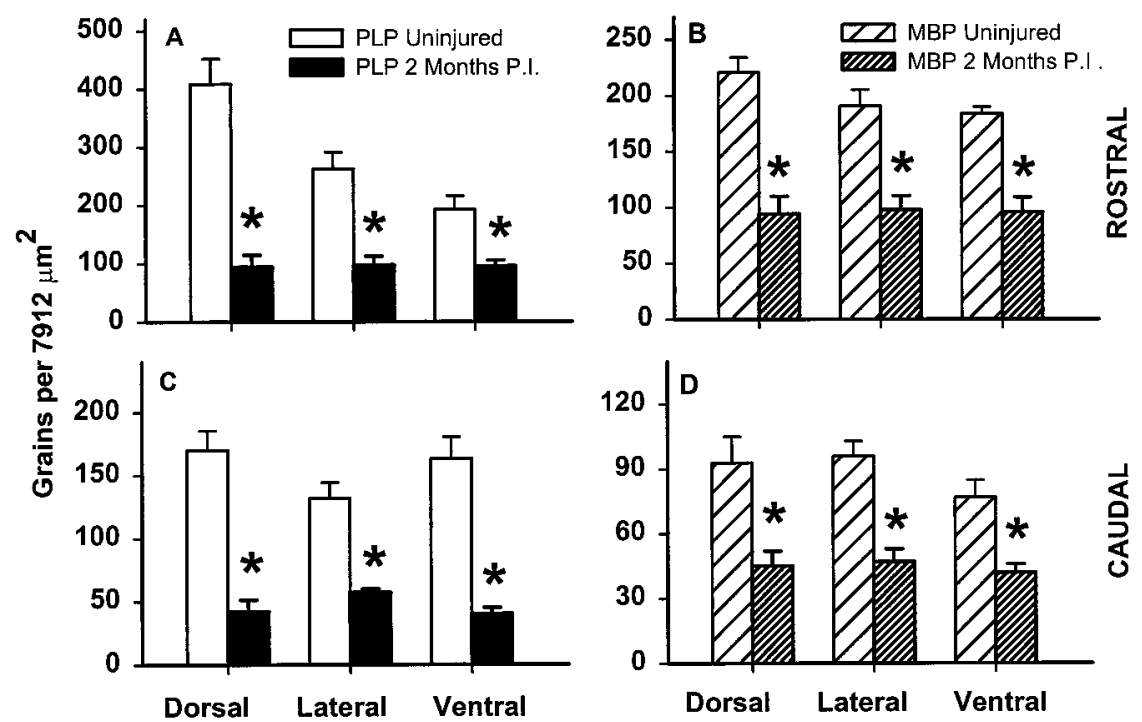

Figure 6. Quantification of the relative expression of PLP and MBP mRNA in normal white matter and residual white matter at 2 months after SCI. White matter in the dorsal, lateral, and ventral funiculi both rostral $(A, B)$ and caudal $(C, D)$ showed significantly reduced grain counts per area for $\operatorname{PLP}(A, C)$ and MBP $(B, D)$ in injured compared with normal tissue mounted on the same slide. Bars represent the mean \pm SEM of grains counted in six sampled areas (7912 $\mu \mathrm{m}^{2}$ each); * indicates values significantly different from uninjured control tissue on the same slide $(t$ test, $p \leq 0.05)$. P.I., Postinjury. and caudal (Fig. 6C,D) to the epicenter showed significantly reduced grain counts per area for MBP and PLP in injured compared with normal tissue. To determine whether this was likely caused by a reduction in the number of myelin geneexpressing cells chronically after SCI, we compared the number of cell nuclei per area positive for grains after hybridization with the PLP probe in normal and injured white matter (Fig. 7A). We found no difference in the number of cells expressing PLP mRNA but a shift in the grain density (grains per cell) as compared with normal for cells in both the dorsal and ventral funicular white matter (Fig. 7B,C). However, the number of unlabeled cells and the total number of cells per area were significantly increased. For example there were $41 \pm 2.7$ nuclei per white matter area in control versus $67 \pm 6.2$ nuclei per white matter area in chronically injured ventral white matter $(t$ test, $p<0.05)$. Similar increases were seen in dorsal and lateral white matter (data not shown), and counts of the ventral gray matter revealed an even greater increase in unlabeled cell density ( $65 \pm 2.5$ vs $167 \pm 15.7)$.

\section{MBP protein chronically after $\mathbf{S C I}$}

Myelin preparations from normal and injured spinal cords contained three major bands of MBP-immunoreactive protein (Fig. $8 A$ ). These corresponded to the 14,17 and 18.5 (not fully resolved in our gels), and $21.5 \mathrm{kDa}$ isoforms characteristic of rodent MBP (Carson et al., 1983; de Ferra et al., 1985). Quantitative analysis (Fig. 8B) indicated a small reduction in MBP protein per microgram of myelin preparation protein that was statistically significant only with respect to band $1(21.5 \mathrm{kDa})$. However, the myelin preparation yield was lower for the injured tissues. Thus, there was a significant reduction in each of the bands and in total MBP protein per gram of spinal cord tissue compared with that in uninjured controls (Fig. 8C).

Immunocytochemistry demonstrated preferential and relatively even MBP staining in the white matter of normal spinal cord tissue (data not shown). At 2 months after SCI there was also considerable staining with antibody to MBP, but in this case it was primarily associated with spherical microcyst-like structures (Fig. 9A) seen in the residual white matter. These MBP-positive structures appeared similar in shape and size to the numerous myelin microcysts seen by electron microscopy at 2 months after injury (Fig. 9B).

\section{PO expression and Schwann cell myelination after $\mathbf{S C I}$}

$\mathrm{P} 0$ expression was not seen in the normal spinal cord or at $7 \mathrm{~d}$ after injury (data not shown) but was characteristically present at 2 and 6 months after SCI both at the epicenter and in the lesioned area of the cord at least $4 \mathrm{~mm}$ distal from the epicenter (Fig. $10 C, G)$. At the epicenter the $\mathrm{P} 0$ expression was seen to be associated both with the dorsal and ventral root entry zones as well as with the central "cavity" that contains loosely arranged cells. Electron microscopy demonstrated that this lesion area contained many axons myelinated by Schwann cells (Fig. 10D,E), as well as nests of ependymal cells and macrophages containing myelin debris. Schwann cell-myelinated axons were distinguished by the presence of cytoplasm, and sometimes the nucleus, of the myelinating cell located externally to the myelin sheath and

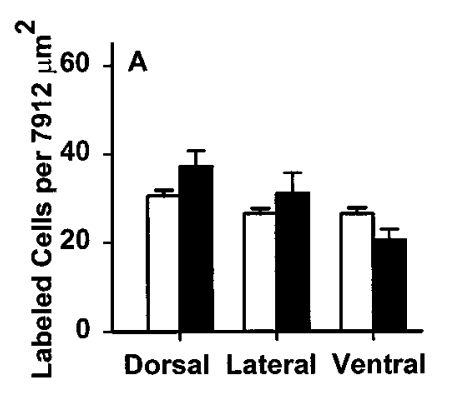

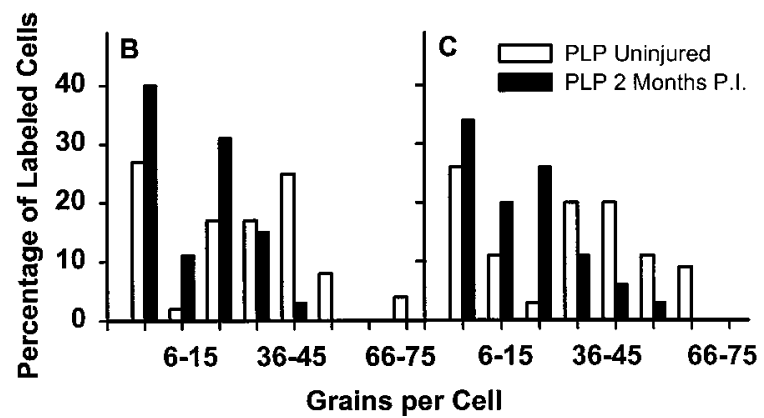

Figure 7. PLP mRNA-expressing cells and the relative expression per cell at 2 months after SCI. $A$, Comparison of the number of cell nuclei per area positive for grains greater than background after hybridization with the PLP probe in normal and injured white matter. Bars represent mean number \pm SEM based on six to eight areas analyzed for each white matter region from sections on the same slide representing normal and chronic injured tissue at $4 \mathrm{~mm}$ rostral to the epicenter. $B, C$, Frequency distributions of net grains per cell in labeled cells in the ventral white matter at $4 \mathrm{~mm}$ rostral $(B)$ and $4 \mathrm{~mm}$ caudal $(C)$ to the epicenter of in-jured compared with normal tissue on the same slides. Net grains (minus background) were counted in $227 \mu \mathrm{m}^{2}$ circles centered on each nucleus in the areas sampled for a total of 35-40 cells analyzed per group. P.I., Postinjury. 
A
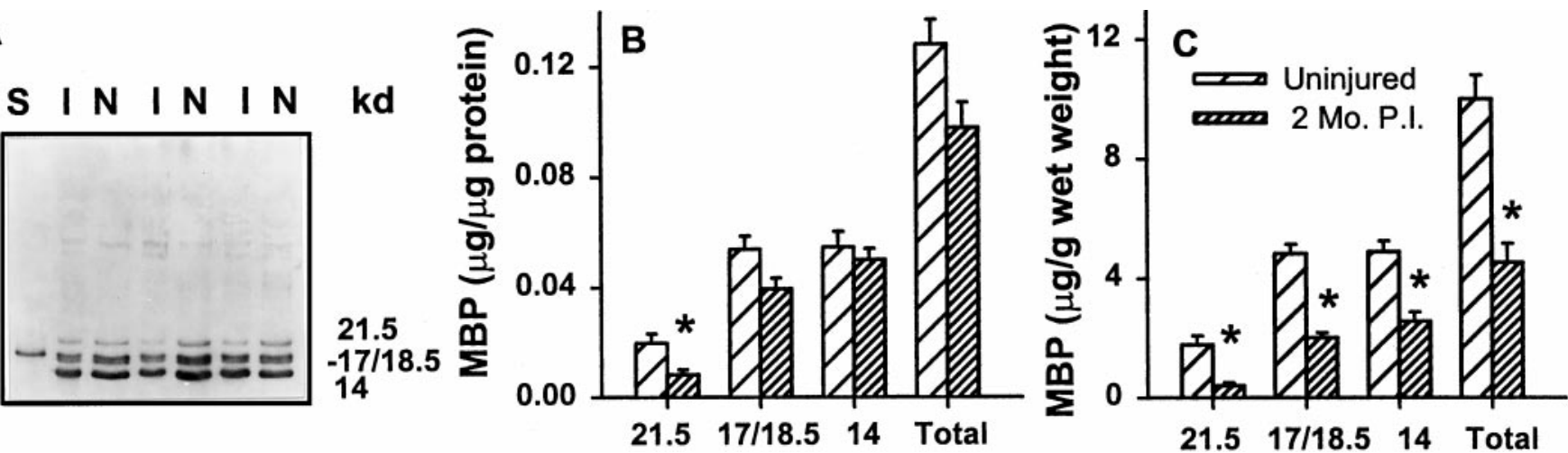

Figure 8. Expression of MBP protein after SCI. A, Western blots showed three major bands of MBP-immunoreactive protein in myelin preparations from normal thoracic spinal cord $(N)$ and in tissue from the injury sites at 2 months after SCI $(I) . S, \mathrm{MBP}$ standard. Molecular weights in kilodaltons $(\mathrm{kDa})$ of the major bands are shown on the right. B, Quantification of MBP bands as micrograms per microgram of total protein applied in normal and injured samples $(n=5)$ shows a significant $\left({ }^{*}\right)$ reduction in band $1(t$ test, $p \leq 0.05)$. $C$, MBP expressed as micrograms per gram wet weight of spinal cord tissue demonstrates significant $\left.{ }^{*}\right)$ reductions in each isoform as well as in total MBP. P.I., Postinjury.

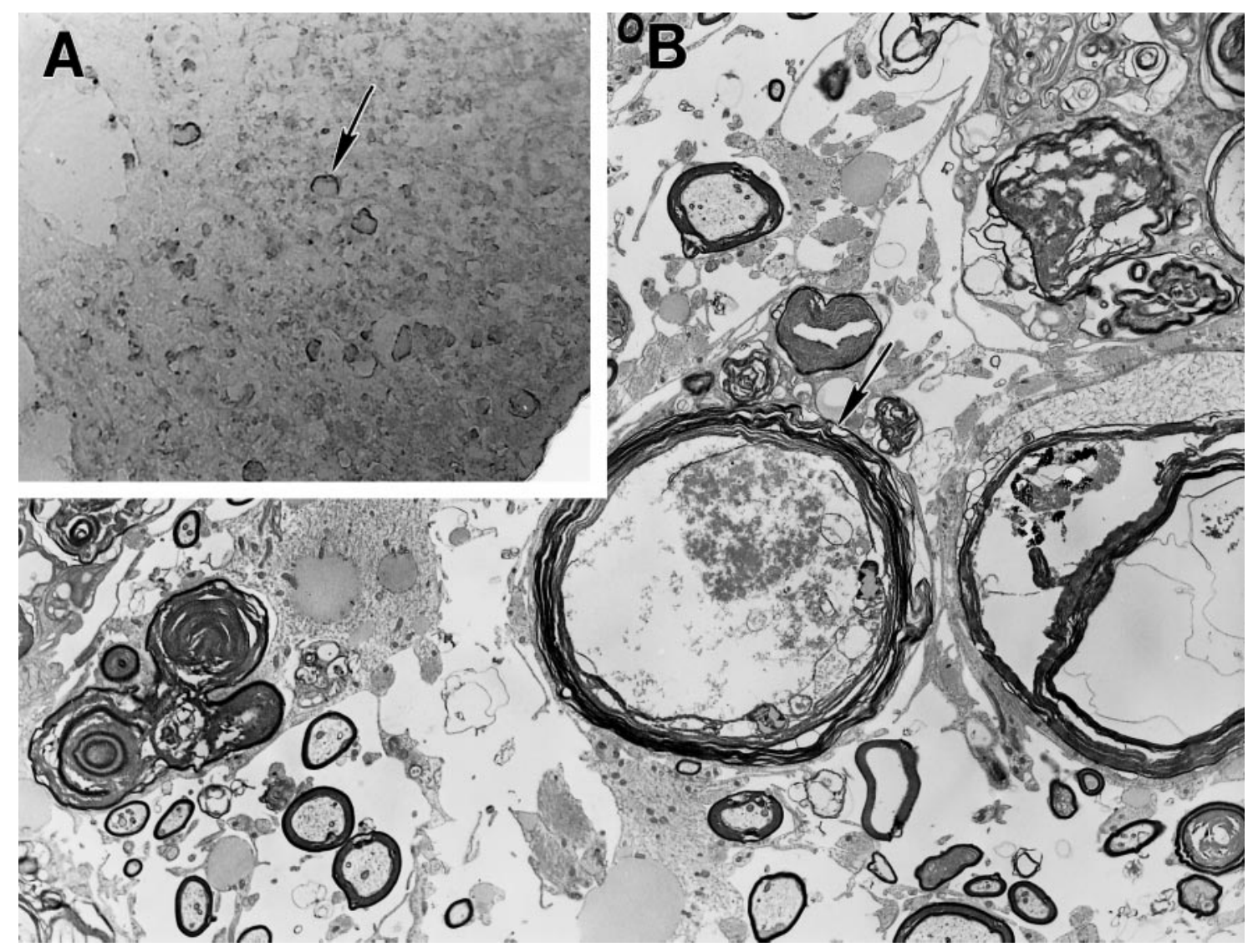

Figure 9. Myelin microcysts and debris at 2 months after SCI. $A$, Immunocytochemistry with antibody to MBP demonstrates staining primarily associated with spherical microcyst-like structures (arrow) seen in the residual white matter of the chronic injury epicenter. $79 \times . B$, Myelin microcysts (arrow) and debris seen by electron microscopy at 2 months after injury are shown. $4250 \times$.

surrounded by a basal lamina (Peters et al., 1991). The thickness of the myelin sheaths appeared normal, although a formal analysis of myelin index was not performed. In some cases, astrocytic processes were seen to separate groups of axons myelinated by Schwann cells (Fig. 10D).

\section{Increased expression of MYT1 after SCI}

MYT1 mRNA expression in the normal spinal cord was barely detected in the white matter and was low in gray matter (Fig. $11 A)$. The expression of MYT1 mRNA appeared to be increased in injured SCI. At 2 months after injury, increased MYT1 expression was seen at the epicenter (Fig. $11 B$ ) and in tissue rostral and caudal to the epicenter (Fig. 11C,D). The increased MYT1 expression was seen primarily in the central gray matter of the cord and was less but not completely absent in the lesioned zone where P0 was highly expressed (compare Figs. 11B, 10C).

Because the oligonucleotide probe for MYT1 is highly homologous to a recently cloned family member of MYT1 named MYT1L (Kim et al., 1997), the elevated hybridization signals 


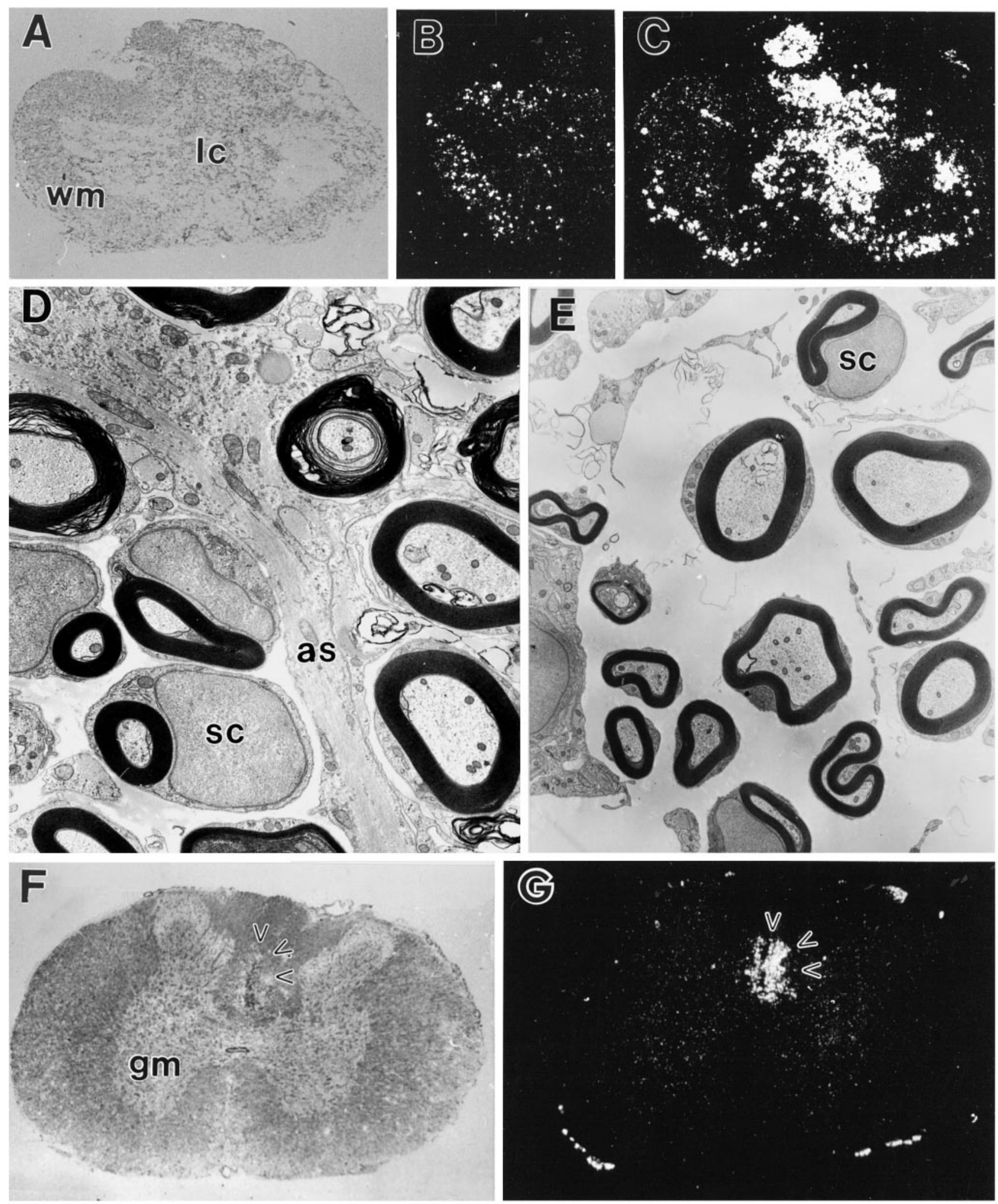

Figure 10. $\mathrm{P} 0$ expression in the chronic injured spinal cord. $A$, SCI epicenter at 2 months after injury with a peripheral rim of residual white matter ( $w m$ ) and cells in the lesion area $(l c)$ within the central cavity is shown. $35 \times . B$, Dark-field microscopy of in situ hybridization demonstrating PLP expression in an adjacent section is reduced and restricted to the peripheral rim of residual white matter. $C, \mathrm{P} 0$ expression is strong both in a circular profile of dorsal root near the top of the field as well as in the lesion zone of the epicenter and also shows an expanded distribution near the dorsal and ventral root entry zones. $D$, Electron microscopy of the junction between residual spinal cord tissue and lesion zone reveals many Schwann cell (sc)-ensheathed axons near an astrocytic process $(a s) .10,000 \times . E$, In the lesion zone at the center of the epicenter, axons myelinated by Schwann cells $(s c)$ are frequently seen. $6000 \times$. F, At $4 \mathrm{~mm}$ caudal to the epicenter, the lesion (arrowheads) is restricted to the dorsal funicular white matter. $28 \times$. $G$, In situ hybridization shows strong expression of P0 mRNA in this lesion area (arrowheads). 

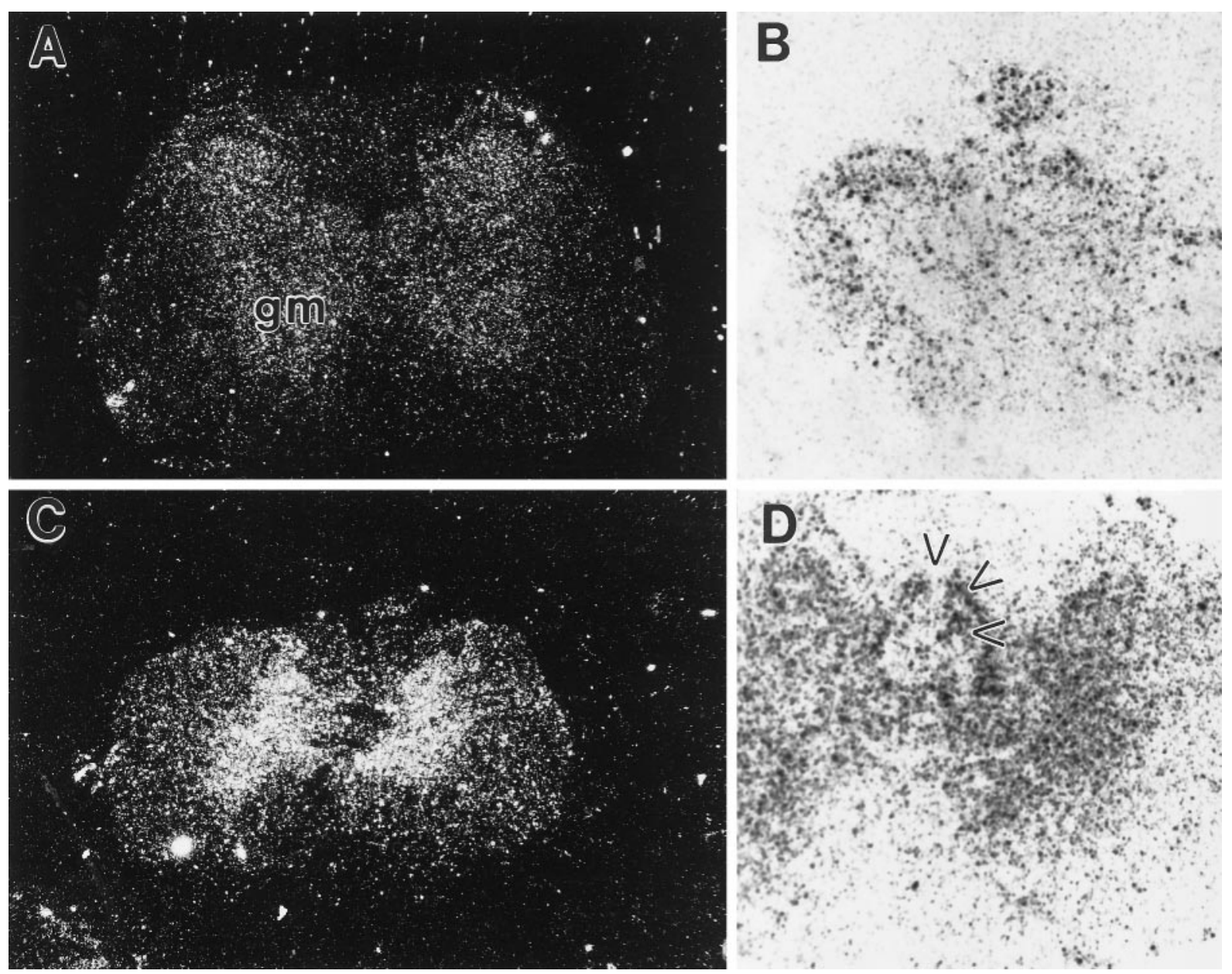

Figure 11. MYT1 mRNA expression in the normal spinal cord and 2 months after SCI. $A$, In the uninjured cord, MYT1 mRNA was barely detected in the white matter and was low in gray matter $(\mathrm{gm}) . B$, MYT1 mRNA expression at the lesion epicenter in a section adjacent to those shown in Figure $10 A-C$ is shown. Expression is seen in the rim of residual white matter, in the central lesion zone, and even in some foci within an expanded dorsal root that appears in Figure $10 C$ to be intensely positive for P0. $C$, At $4 \mathrm{~mm}$ rostral to the epicenter, MYT1 is increased both in white matter and especially in gray matter. $D$, At $4 \mathrm{~mm}$ caudal to the injury site, in a section adjacent to those shown in Figure 10, $F$ and $G$, MYT1 mRNA appears primarily but not completely absent in the lesion zone where PO expression is intense (Fig. 10G) and seems especially prominent immediately adjacent to the lesion zone (arrowheads). A, C: Dark field, 26×. B, D: Bright field, $38 \times$.

found with MYT1 could reflect in part an overexpression of MYT1L, a gene whose expression is restricted to the neuronal lineage during development and is found in neurons at the time of their terminal mitosis. To assess the relative expression of MYT1 and MYT1L after SCI, we used antibodies generated against portions of MYT1 (Armstrong et al., 1995) or MYT1L (Kim et al., 1997). Both MYT1 and MYT1L were overexpressed in distinct cell populations of the injured spinal cord. In normal rat, immunostaining for MYT1 (Fig. 12A) was detectable primarily in cells forming the central canal and some neurons in the gray matter. Although there was also some staining of glia in white matter, it was mostly in the lateral rather than the dorsal or ventral funiculi. Six weeks after SCI, the immunostaining for MYT1 was elevated, both at the lesion epicenter (Fig. 12C) and at least $4 \mathrm{~mm}$ distally (Fig. $12 E, G, J$ ). MYT1 at the epicenter (Fig. 12C) was high in the peripheral rim of preserved white matter but was also seen in the central lesioned zone. Distal to the epicenter there was increased expression in neurons of the gray matter as well as in cells in the white matter (Fig. 12E), especially the ventral medial white matter (Fig. $12 G$ ) adjacent to the ventral

MYT1 expression is still greater than that in normal cord both in large neurons in the gray matter and in the white matter. $F$, An adjacent section shows increased MYT1L immunoreactivity. $G$, The most intense MYT1 expression is in the ventromedial white matter (boxed region in $E$ ) where many nuclei of small round cells are positive as well as in the cytoplasm of cells with the morphology of astrocytes. $H$, Enlargement of the boxed region in $B$ shows MYT1L immunoreactivity only in the most superficial layers of the dorsal horn of normal spinal cord. I, Similar enlargement of the dorsal horn (boxed region in $F$ ) indicates that after SCI the proportion of MYT1L-labeled cells is much increased. $J$, Double immunocytochemistry for MYT1 (brown) and GFAP (blue) shows that reactive astrocytes in white matter express both antigens (arrow) in their hypertrophic processes. MYT1-positive nuclei (arrowhead) are also present in many GFAP-negative cells. K, Double immunocytochemistry for MYT1L (brown) and GFAP (blue) shows that some reactive astrocytes in white matter express both antigens (arrow); other astrocytic processes are MYT1L-negative. MYT1L staining is seen in the nuclei of GFAP-negative cells in the white matter (small arrowhead) and in both the nucleus and cytoplasm of large ventral horn neurons (large arrowhead) in the adjacent gray matter. $c c$, Central canal; $d f u$, dorsal funiculus; $G M$, gray matter; lfu, lateral funiculus; $v f u$, ventral funiculus. $A-F: 35 \times$. $G-I: 135 \times . J, K: 320 \times$. 

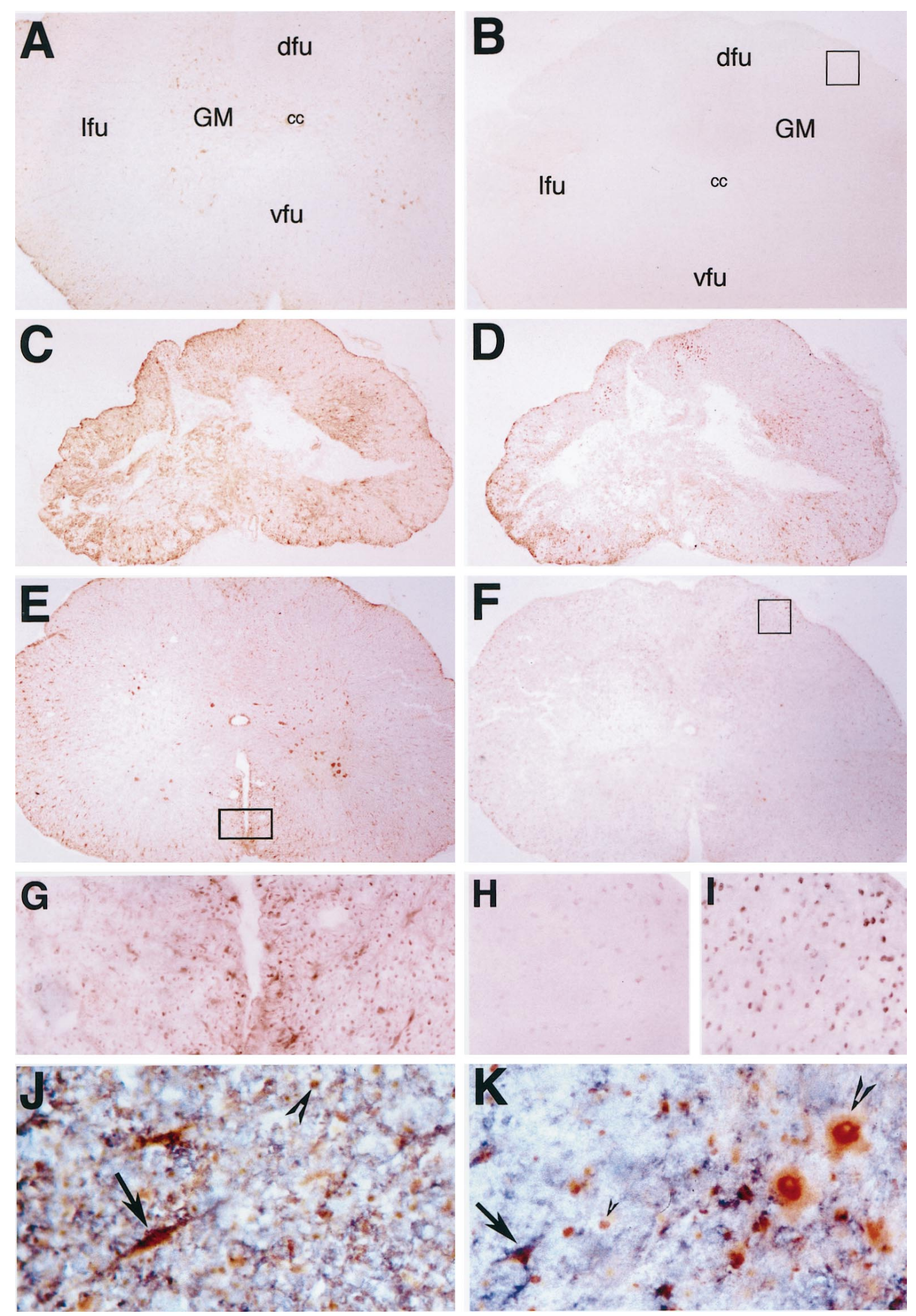

Figure 12. Immunostaining for MYT1 $(A, C, E, G, J)$ and MYT1L $(B, D, F, H, I, K)$ proteins in normal and injured spinal cord. $A$, In the normal spinal cord, MYT1 immunoreactivity is present in cells of the central canal, in large neurons in the gray matter, and to a lesser extent in cells in the white matter. $B$, MYTL1 immunoreactivity in the uninjured cord is very faint. $C$, At the lesion epicenter 6 weeks after SCI, the intensity of MYT1 immunostaining is increased both in the peripheral rim of preserved white matter and in the central lesion zone. D, MYT1L staining at the epicenter in an adjacent section is also increased but limited to portions of the peripheral rim of white matter. E, Four millimeters distal to the epicenter, (Figure legend continues) 
median fissure. Two types of MYT1 staining were observed. There was staining of virtually all of the hypertrophic astrocytic processes (Fig. 12G) as confirmed by GFAP and MYT1 double immunostaining (Fig. 12J); no nuclear staining for MYT1 was detected in astrocytes. In addition, many nuclei of small round GFAP-negative cells expressed MYT1 (Fig. 12G,J). As shown in Figure 13, these cells with MYT1-positive nuclei were distinct from mature oligodendrocytes labeled with antibody to $\mathrm{CC} 1$ and from microglia stained with the OX42 antibody.

The staining with MYT1L antibody in normal spinal cord (Fig. $12 B$ ) was limited to the nuclei of cells in the first two layers of dorsal horn gray matter, where staining was barely detectable (Fig. 12H). Six weeks after injury, MYT1L expression was increased, perhaps to a relatively greater extent than was MYT1. Elevated nuclear staining for MYT1L was seen throughout the gray matter (Fig. 12F,I), and some neurons also demonstrated cytoplasmic immunoreactivity (Fig. 12K). MYT1L immunostaining appeared increased at the epicenter after SCI (Fig. 12D) where it was restricted to the peripheral rim of surviving white matter. White matter distal to the epicenter (Fig. $12 F$ ) also demonstrated increased staining; some reactive astrocytes were positive as well as the nuclei of a number of GFAP-negative cells (Fig. 12K).

\section{DISCUSSION}

Our results demonstrate chronic alterations in the myelination of axons after experimental contusion injury of the spinal cord associated with chronic alterations in myelin gene expression. These include apparent downregulation of mRNA for PLP and $\mathrm{MBP}$, major structural proteins in CNS myelin, expression of $\mathrm{P} 0$, usually only found in the PNS, and increased expression of MYT1, a gene associated with the transcriptional regulation of myelin proteins and normally expressed during development and in progenitor cells of the adult CNS.

We found that the residual white matter in the peripheral rim of preserved tissue that we evaluated previously by light microscopy (e.g., Noble and Wrathall, 1985; Teng and Wrathall, 1997) exhibits profound ultrastructural abnormalities. These include reduced numbers of axons compared with that in normal white matter, particularly large myelinated axons. This is consistent with reports on residual white matter in chronically contused ferret (Eidelberg et al., 1977), cat (Blight, 1983a), and rat (Salgado-Ceballos et al., 1998) spinal cords. It is also consistent with our finding significant axonal loss, especially of large axons, $4 \mathrm{hr}$ after contusion in the rat SCI model used in the current study (Rosenberg and Wrathall, 1997). We also found abnormal myelination, particularly hypomyelination, reflected in a shift of the myelin index of axons in chronic SCI tissue, consistent with previous data from the rat (Salgado-Ceballos et al., 1998) and from cat, where hypomyelination was associated with abnormalities of impulse conduction (Blight, 1983b).

Reduced myelination could result from loss of myelinating cells and/or reduced myelin synthesis by surviving oligodendrocytes. There is a prolonged loss of oligodendrocytes via apoptosis after SCI (e.g., Crowe et al., 1997). This seems to be associated with Wallerian degeneration of axons, involves the loss of only a small portion of cells at any particular time, and thus might not significantly affect the ratio of oligodendrocytes to axons. We found that the concentration of myelinating cells (cells per area) that express PLP mRNA is not significantly reduced in the chronically injured spinal cord. However, the amount of PLP mRNA per cell is reduced, and more cells than normal appear to express low levels. MBP mRNA cannot be similarly studied at the cellular level because it is not restricted to a perinuclear distribution (Zeller et al., 1985). However, based on area counts, its reduction is at least equal to that of PLP. Because myelin synthesis seems to be regulated at the transcriptional level (Cook et al., 1992), our results suggest that the hypomyelination of surviving axons after SCI may be caused, at least in part, by transcriptional downregulation in oligodendrocytes over a distance of many millimeters in the chronically injured rat spinal cord.

This conclusion must be considered tentative. We do not know that the rate of myelin synthesis is actually reduced. That there is reduced myelin in the injured cord is clearly established by the combination of morphological and biochemical techniques used in this study. Western analysis showed reduced MBP bands, and immunocytochemistry showed that much of what remains is in inclusion bodies. In combination with the evidence of reduced mRNA levels for both MBP and PLP, our data suggest, but do not prove, that there is reduced myelin synthesis in the injured spinal cord. This may reflect the reduced numbers of axons after SCI and/or may contribute to the hypomyelination that characterizes many of these axons.

In either case, the abnormal myelination seen in the chronically injured spinal cord raises important and interesting questions. Do surviving axons provide an inadequate signal for normal myelination by oligodendrocytes? Are many of the myelinating cells damaged by SCI so that they can no longer respond normally to the axonal signal(s) for myelination? Are a significant proportion of the myelinating cells after SCI derived from precursors present in adult white matter (Armstrong et al., 1992) but incapable of myelinating axons in a normal manner? In this respect, the recent report (Shihabuddin et al., 1997) that a progenitor cell population can be isolated from adult rat spinal cord and stimulated to divide with basic fibroblast growth factor (FGF2) is of considerable interest. Cells in these cultures differentiated into both neuronal and glial cell types, including oligodendrocytes. Because FGF2 mRNA and protein are upregulated in the spinal cord after SCI (Follesa et al., 1994; Mocchetti et al., 1996), a similar stimulation of proliferation of progenitor cells may occur in vivo. Our data suggest that the increased number of cells in the white matter that are PLP-negative may include representatives of such a progenitor cell population that express MYT1 and/or MYT1L.

The presence of Schwann cells and axons ensheathed with PNS myelin in the injured spinal cord at chronic time points has been noted in previous studies (e.g., Griffiths and McCulloch, 1983). There is also electrophysiological evidence that Schwann cellmyelinated axons in the chronically injured spinal cord conduct impulses (Blight and Young, 1989). Our results confirm and extend these earlier studies. It is intriguing that P0 expression is high in the tapered distal extensions of the lesion characteristically present in the dorsal funiculus just above the gray matter, an area that normally includes corticospinal axons in the rat. Thus, an interesting question is whether any surviving corticospinal axons become myelinated by Schwann cells or whether the area becomes repopulated with other types of axons from the CNS, or with sensory axons from the dorsal roots.

The abnormally thin myelin seen in residual white matter chronically after SCI is thought to arise from a demyelinationremyelination sequence of events (Blight, 1993). Evidence of demyelination after SCI has been reported by a number of investigators (Balentine, 1978; Bresnahan, 1978; Griffiths and McCulloch, 1983; Bunge et al., 1994; Rosenberg and Wrathall, 1997). Remyelination after SCI may be performed by the surviving mature oligodendrocytes and/or oligodendrocyte progenitors 

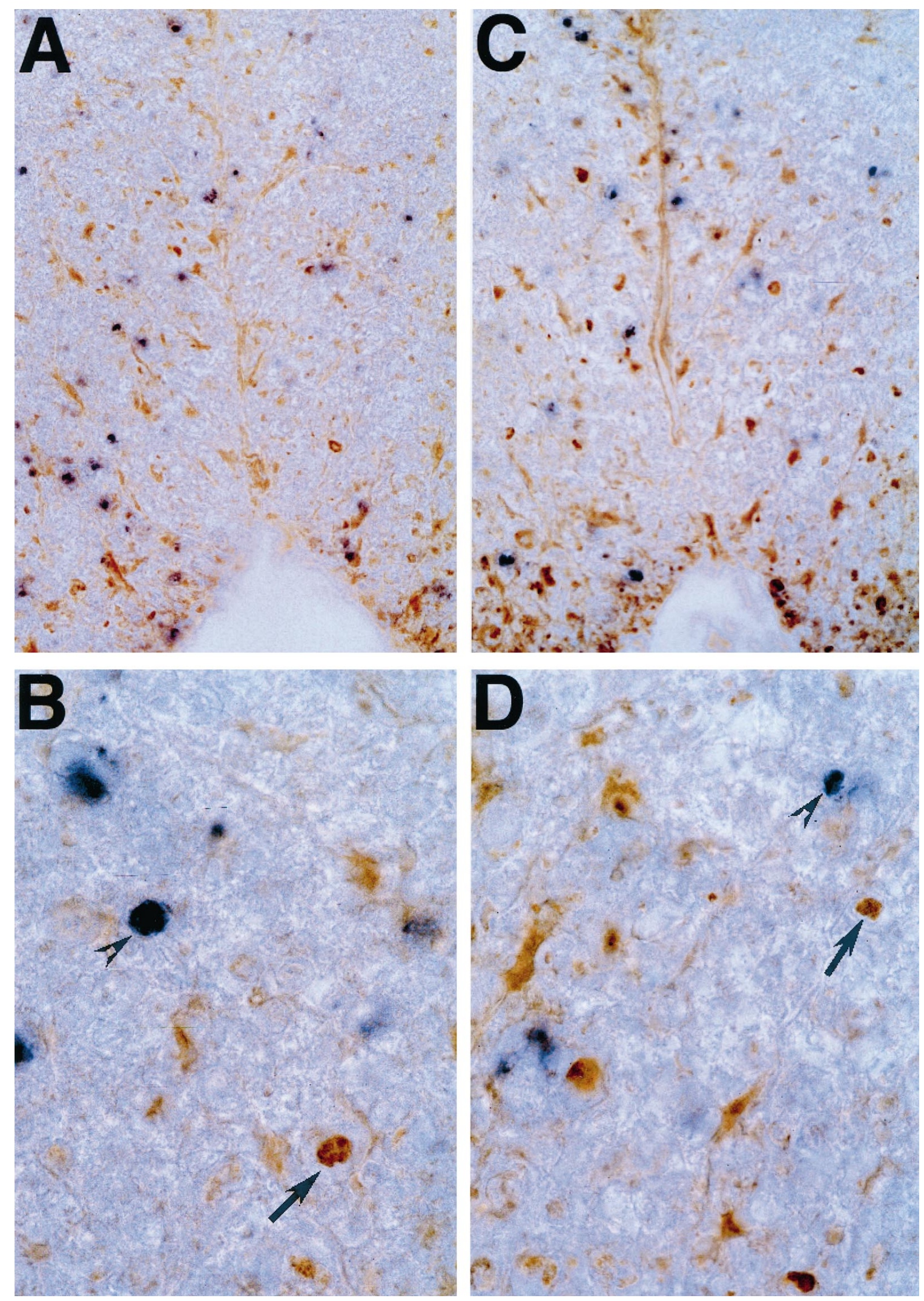

Figure 13. Double immunostaining for MYT1 and the oligodendrocyte marker CC1 $(A, B)$ or the microglial marker OX42 $(C, D)$. At 6 weeks after injury, sections $4 \mathrm{~mm}$ from the epicenter demonstrate ventromedial immunostaining for MYT1 (brown) as well as CC1 (blue; $A, B)$ and OX42 (blue; $C$, $D$ ). However, at high magnification, no colocalization of MYT1 (arrow) staining was seen with CC1 (B, arrowhead) or OX42 (D, arrowhead). $A, C$ : $280 \times$. $B, D: 630 \times$. 
that could be stimulated to differentiate and myelinate after injury. We used two approaches to examine the role of progenitor cells in remyelination. One was to characterize the isoforms of myelin proteins present after injury, because progenitor cells induced to myelinate follow a typical developmental pattern in which exon 2-containing MBP isoforms (21 and $18 \mathrm{kDa}$ ) are initially highly expressed. The other approach was to assess alterations in the distribution and size of the progenitor pool after SCI using transcription factor markers of oligodendrocyte (MYT1) and neuronal (MYT1L) progenitors (Armstrong et al., 1995, 1997; Kim et al., 1997).

We found MYT1 mRNA and protein were elevated after SCI. The most intense concentration of MYT1-positive cells was in ventromedial white matter (Fig. 12G), reminiscent of the ventral origin of oligodendrocyte progenitor cells in the developing spinal cord (for review, see Richardson et al., 1997). These cells with nuclear MYT1 staining were not positive for astrocyte, microglial, or mature oligodendrocyte markers. They seem to represent a population of glial progenitor cells present in the chronically injured spinal cord that are distinct from reactive astrocytes expressing cytoplasmic MYT1.

Apart from this putative glial progenitor cell population marked by MYT1, another cell population was revealed with an antibody to a closely related family member, MYT1L (Kim et al., 1997). Restricted to the neuronal lineage in normal development, MYT1L-positive cells were conspicuous throughout the gray matter of the injured spinal cord. Thus, both neuronal (MYT1Lpositive) and glial (MYT1-positive) progenitor cells may have been stimulated to divide and/or been recruited to the site of injury.

The presence of cells expressing MYT1 or MYT1L hints that a block in the developmental progression of these cells exists chronically after SCI injury. Our finding a significantly increased cell density in white matter of the chronically injured cord, cells not expressing detectable levels of PLP mRNA, is consistent with this hypothesis. In injured tissue, the relative depletion of the 21.5 $\mathrm{kDa}$ isoform of MBP (Fig. 8), which is normally one of the first $\mathrm{MBP}$ proteins expressed in oligodendrocyte development (Carson et al., 1983), also suggests that oligodendrocyte precursors present in the lesion have not been induced to fully differentiate and myelinate axons. We postulate that the remyelination after SCI, marked by thin myelin sheaths, was likely performed by mature oligodendrocytes that survived the injury and continue to express myelin protein isoforms characteristic of mature cells. Future studies examining the survival of oligodendrocytes after SCI and the origin and fate of cells expressing MYT1 and MYT1L will be needed to test these hypotheses.

In summary, we found that chronically after incomplete contusive SCI there is abnormal myelination of residual axons that may be caused, at least in part, by changes in transcriptional regulation of genes for myelin proteins. There is also a dramatically altered distribution of myelin-producing cells with substantial Schwann cell myelination in the lesion zone. Additionally, an increased cell density in residual white matter is associated with increased expression of MYT1, a transcription factor present in oligodendrocyte precursors. These data suggest the presence of undifferentiated progenitor cells in the chronically injured cord. Thus, the abnormal myelination of spared axons after SCI may be less a problem of oligodendrocyte cell death than a problem in the signaling pathways that normally lead to differentiation of progenitor cells and their participation in axonal (re)myelination.

\section{REFERENCES}

Armstrong RC, Dorn HH, Kufta CV, Friedman E, Dubois-Dalcq ME (1992) Pre-oligodendrocytes from adult human CNS. J Neurosci 12:1538-1547.

Armstrong RC, Kim JG, Hudson LD (1995) Expression of myelin transcription factor I (MyTI), a "zinc-finger" DNA-binding protein, in developing oligodendrocytes. Glia 14:303-321.

Armstrong RC, Migneault A, Shegog ML, Kim JG, Hudson LD, Hessler RB (1997) High-grade human brain tumors exhibit increased expression of myelin transcription factor 1 (MYT1), a zinc finger DNAbinding protein. J Neuropathol Exp Neurol 56:772-781.

Balentine JD (1978) Pathology of experimental spinal cord trauma. II. Ultrastructure of axons and myelin. Lab Invest 39:254-266.

Bhat RV, Axt KJ, Fosnaugh JS, Smith KJ, Johnson KA, Hill DE, Kinzler KW, Baraban JM (1996) Expression of the APC tumor suppressor protein in oligodendroglia. Glia 17:169-174.

Blight AR (1983a) Cellular morphology of chronic spinal cord injury in the cat: analysis of myelinated axons by line-sampling. Neuroscience 10:521-543.

Blight AR (1983b) Axonal physiology of chronic spinal cord injury in the cat: intracellular recording in vitro. Neuroscience 10:1471-1486.

Blight AR (1993) Remyelination, revascularization, and recovery of function in experimental spinal cord injury. Adv Neurol 59:91-104.

Blight AR, Young W (1989) Central axons in injured cat spinal cord recover electrophysiological function following remyelination by Schwann cells. J Neurol Sci 91:15-34.

Bracken MB, Shepard MJ, Collins WF, Holford TR, Young W, Baskin DS, Eisenberg HM, Flamm E, Leo-Summers L, Maroon PH, Marshall LF, Perot PL, Piepmeier J, Sonntag VKH, Wagner FC, Wilberger JE, Winn HR (1990) A randomized, controlled trial of methylprednisolone or naloxone in the treatment of acute spinal-cord injury. Results of the Second National Acute Spinal Cord Injury Study. N Engl J Med 322:1405-1411.

Bresnahan JC (1978) An electron-microscopic analysis of axonal alterations following blunt contusion of the spinal cord of the rhesus monkey (Macaca mulatta). J Neurol Sci 37:59-82.

Bunge MB, Holets VR, Bates ML, Clarke TS, Watson BD (1994) Characterization of photochemically induced spinal cord injury in the rat by light and electron microscopy. Exp Neurol 127:76-93.

Bunge RP, Puckett WR, Becerra JL, Marcillo A, Quencer RM (1993) Observations on the pathology of human spinal cord injury. A review and classification of 22 new cases with details from a case of chronic cord compression with extensive focal demyelination. Adv Neurol 59:75-89.

Carson JH, Nielson ML, Barbarese E (1983) Developmental regulation of myelin basic protein expression in mouse brain. Dev Biol 96:485-492.

Cook JL, Irias-Donaghey S, Deininger PL (1992) Regulation of rodent myelin proteolipid protein gene expression. Neurosci Lett 137:56-60.

Crowe MJ, Bresnahan JC, Shuman SL, Masters JN, Beattie MS (1997) Apoptosis and delayed degeneration after spinal cord injury in rats and monkeys. Nat Med 3:73-76.

de Ferra F, Engh H, Hudson L, Kamholz J, Puckett C, Molineaux S, Lazzarini RA (1985) Alternative splicing accounts for the four forms of myelin basic protein. Cell 43:721-727.

Eidelberg E, Straehley D, Erspamer R, Watkins CJ (1977) Relationship between residual hindlimb-assisted locomotion and surviving axons after incomplete spinal cord injuries. Exp Neurol 56:312-322.

Follesa P, Wrathall JR, Mocchetti I (1994) Increased basic fibroblast growth factor mRNA following contusive spinal cord injury. Brain Res Mol Brain Res 22:1-8.

Gale K, Kerasidis H, Wrathall JR (1985) Spinal cord contusion in the rat: behavioral analysis of functional neurologic impairment. Exp Neurol 88:123-134.

Gledhill RF, Harrison BM, McDonald WI (1973) Demyelination and remyelination after acute spinal cord compression. Exp Neurol 38:472-487.

Griffiths IR, McCulloch MC (1983) Nerve fibres in spinal cord impact injuries. Part 1 . Changes in the myelin sheath during the initial 5 weeks. J Neurol Sci 58:335-349.

Hansebout RR, Blight AR, Fawcett S, Reddy K (1993) 4-Aminopyridine in chronic spinal cord injury: a controlled, double-blind, crossover study in eight patients. J Neurotrauma 10:1-18.

Hayes KC, Potter PJ, Wolfe DL, Hsieh JT, Delaney GA, Blight AR 
(1994) 4-Aminopyridine-sensitive neurologic deficits in patients with spinal cord injury. J Neurotrauma 11:433-446.

Hsu SM, Raine L, Fanger H (1981) Use of avidin-biotin-peroxidase complex $(\mathrm{ABC})$ in immunoperoxidase techniques: a comparison between $\mathrm{ABC}$ and unlabeled antibody (PAP) procedures. J Histochem Cytochem 29:577-580.

Hudson LD (1990) Molecular biology of myelin proteins in the central and peripheral nervous systems. Semin Neurosci 2:483-496.

Hudson LD, Kim JG, Wiese C, Yao D-L, Liu X, Webster Hd, Agoston VD, Armstrong R (1997) Transcriptional controls in the oligodendrocyte lineage. In: Molecular signaling and regulation in glial cells: a key to remyelination and functional repair (Jeserich G, Althaus $\mathrm{HH}$, Richter-Landsberg C, Heumann R, eds), pp 182-190. New York: Springer.

Kim JG, Hudson LD (1992) Novel member of the zinc finger superfamily: a $\mathrm{C} 2-\mathrm{HC}$ finger that recognizes a glia-specific gene. Mol Cell Biol 12:5632-5639.

Kim JG, Armstrong RC, Agoston VD, Robinsky A, Wiese C, Nagle J, Hudson LD (1997) Myelin transcription factor 1 (Myt1) of the oligodendrocyte lineage, along with a closely related CCHC zinc finger, is expressed in developing neurons in the mammalian central nervous system. J Neurosci Res 50:272-290.

Laemmli UK, Favre M (1973) Maturation of the head of bacteriophage T4. I. DNA packaging events. J Mol Biol 80:575-599.

Li GL, Brodin G, Farooque M, Funa K, Holtz A, Wang WL, Olsson Y (1996) Apoptosis and expression of Bcl-2 after compression trauma to rat spinal cord. J Neuropathol Exp Neurol 55:280-289.

Liu XZ, Xu XM, Hu R, Du C, Zhang SX, McDonald JW, Dong HX, Wu YJ, Fan GS, Jacquin MF, Hsu CY, Choi DW (1997) Neuronal and glial apoptosis after traumatic spinal cord injury. J Neurosci 17:5395-5406.

Lowry OH, Rosebrough NJ, Farr AL, Randall RJ (1951) Protein measurement with the Folin phenol reagent. J Biol Chem 193:265-275.

Mocchetti I, Rabin SJ, Colangelo AM, Whittemore SR, Wrathall JR (1996) Increased basic fibroblast growth factor expression following contusive spinal cord injury. Exp Neurol 141:154-164.

Noble LJ, Wrathall JR (1985) Spinal cord contusion in the rat: morpho- metric analyses of alterations in the spinal cord. Exp Neurol 88:135-149.

Noble LJ, Wrathall JR (1989) Correlative analyses of lesion development and functional status after graded spinal cord contusive injuries in the rat. Exp Neurol 103:34-40.

Norton WT, Poduslo SE (1973) Myelination in rat brain: method of myelin isolation. J Neurochem 21:749-757.

Peters A, Palay SL, Webster Hd (1991) The fine structure of the nervous system, 3rd Edition. New York: Oxford.

Richardson WD, Pringle NP, Yu WP, Hall AC (1997) Origins of spinal cord oligodendrocytes: possible developmental and evolutionary relationships with motor neurons. Dev Neurosci 19:58-68.

Rosenberg LJ, Wrathall JR (1997) Quantitative analysis of acute axonal pathology in experimental spinal cord contusion. J Neurotrauma 14:823-838.

Salgado-Ceballos H, Guizar-Sahagun G, Feria-Velasco A, Grijalva I, Espitia L, Ibarra A, Madrazo I (1998) Spontaneous long-term remyelination after traumatic spinal cord injury in rats. Brain Res 782:126-135.

Shihabuddin LS, Ray J, Gage FH (1997) FGF-2 is sufficient to isolate progenitors found in the adult mammalian spinal cord. Exp Neurol 148:577-586.

Shuman SL, Bresnahan JC, Beattie MS (1997) Apoptosis of microglia and oligodendrocytes after spinal cord contusion in rats. J Neurosci Res 50:798-808.

Teng YD, Wrathall JR (1997) Local blockade of sodium channels by tetrodotoxin ameliorates tissue loss and long-term functional deficits resulting from experimental spinal cord injury. J Neurosci 17:4359-4366.

Wrathall JR, Pettegrew RK, Harvey F (1985) Spinal cord contusion in the rat: production of graded, reproducible, injury groups. Exp Neurol 88:108-122.

Zeller NK, Behar TN, Dubois-Dalcq ME, Lazzarini RA (1985) The timely expression of myelin basic protein gene in cultured rat brain oligodendrocytes is independent of continuous neuronal influences. J Neurosci 5:2955-2962. 